\title{
Registry Study for Type 2 Diabetes Mellitus in a Diabetic Center in Saudi Arabia with Comparative Analysis for Controlled Versus Uncontrolled Cases
}

\author{
Najim A. Abdulwahid* \\ Diabetic Center, King Salman Hospital, MOH.PO Box 56773 Riyadh, Saudi Arabia 11564.
}

Received: October 11, 2016; Accepted: November 07, 2016; Published: December 10, 2016

*Corresponding author: Najim A. Abdulwahid, MD, PhD, Diabetic Center, King Salman Hospital, MOH,PO Box 56773 Riyadh, Saudi Arabia 11564, Tel: +966502130691;E-mail:jan.bernaba@nagyresearch.com

\section{Abstract}

Background Aims: Comparative analysis of 109 controlled cases versus 120 uncontrolled cases to see the outcome for different treatment methods in type 2 Diabetes Mellitus.

Materials and Methods: The study was conducted in a Diabetic Center, included 229 Type 2 Diabetic Patients with mean age of $49.6 \pm 12.6$ years. $1.7 \%$ of patients were on diet only, $69 \%$ on oral hypoglycemic drugs, $4.8 \%$ on Insulin and $24.5 \%$ on combined insulin \& oral hypoglycemic drugs.

Results: Vitamin D Level increased from 31.3 to $70.3 \mathrm{ng} / \mathrm{ml}$ and 31.4 to $69.6 \mathrm{ng} / \mathrm{ml}$ in controlled \& uncontrolled patients between beginning \& end of the study. Total cholesterol, HDL-C, LDL-C \& TG improved by $-11.2 \% \&-4.8 \%,+19.8 \% \&+3.1 \%, \quad-11.1 \% \& 0.8 \%$ and $-30.4 \% \&-3.4 \%$ in controlled \& uncontrolled patients respectively.

Hba1c decreased by $15.4 \%$ in controlled patients, and by $6.0 \%$ in uncontrolled DM patients; $(p=0.007)$. FBG also decreased by $24.9 \%$ and $8.1 \%$, for controlled and uncontrolled DM patients. Vitamin D level was investigated in both groups; vitamin D increase ( $p$-value 0.000 ) has an effect on diabetes mellitus type 2 control. A better lipid profile was seen with controlled patients than uncontrolled patients.

Conclusion: Controlled diabetic patients showed better clinical outcomes than uncontrolled patients regarding lipid profile, HbA1c, FBG and Vitamin D deficiency. Strict diabetes control regulates TG and HDL-C, which in turn decreases CV risk. Profile;

Keywords: Diabetes Mellitus type II; Control, Vitamin D; Lipid

\section{Introduction}

Type 2 Diabetes Mellitus [DM] incidence is increasing worldwide, and it can be due to many risk factors such as genetic, environmental or behavioral factors. ${ }^{[1]}$ It is suggested through epidemiological data that $90 \%$ of type 2 diabetes cases are due to lifestyle and modifiable habits. [2] The main non-genetic risk factor is obesity. So, weight loss was shown to delay type $2 \mathrm{DM}$, however solely it is hard to maintain and depend on. [3-5]
Previous studies concluded that type 2 DM causes various microvascular [6-7] and macrovascular [8-9] complications, such as stroke [10], neuropathy [7], myocardial infarctions [6,11] and mortality $[9,12]$. The previous factors are due to the different glycaemia impairment thresholds. The risk of microvascular disorders is with extreme glycaemia concentrations, whereas it is believed that the risk of myocardial infarction increases with any increase in glycaemia. [13-14]

Prospective studies have shown that the majority of diabetic people become disabled or die due to vascular complications' consequences. [15] Glycated hemoglobin levels in addition to glycaemia levels are associated with major vascular complications. ${ }^{[16]}$ Current guidelines recommendations for diabetic patients is to reach $\mathrm{HbA1c}$ of $7.0 \%$ or less. [17]

According to the International Diabetes Federation, Saudi Arabia is nationally considered one of the highest countries in the prevalence of diabetes around the world, as per the International Diabetes Federation ${ }^{[18]}$. Over the past few decades, Saudi Arabia has become a prompt developing country, where people's lifestyle has shifted to urbanization. It has been suggested by former studies that diabetes is present epidemically in Saudi Arabia, especially in urban areas. [19]

In this study we aim to compare between controlled and uncontrolled type 2 diabetic patients. The patient's FBG and HbA1c were assessed at the beginning and end of the study. Also, the patients' lipid profile was assessed and compared, since dyslipidemia [20] frequently accompanies diabetes type 2, increasing the risk of cardiovascular disease and hypertension.

\section{Materials and Methods}

An observational study was carried out on 229 Type 2 Diabetes Mellitus patients at a Diabetic Center in Riyadh, Saudi Arabia for four months enrollment between the $1^{\text {st }}$ of January 2013 and $31^{\text {st }}$ of March 2013. The statistical analysis will include: 
Descriptive statistics included frequency tables (n, mean, median and standard deviation for continuous variables and $n$, frequency and percentage for categorical values). To test the differences between controlled and uncontrolled patients; paired t-test at $95 \%$ Confidence Interval was performed.

The patients were classified into two groups; 120 (52.4\%) controlled and 109 (47.6\%) uncontrolled, according to level of HbA1c and/or FBG, so patients with HbA1c of $7 \%$ or less are in the controlled group and if above $7 \%$ are in the uncontrolled group and FBG of $7 \mathrm{mmol} / \mathrm{L}$ or less are in the controlled group and above $7 \mathrm{mmol} / \mathrm{L}$ are in the uncontrolled group.

Out of the total 229 patients; 120 were controlled patients $63(52.5 \%)$ were males and 57 (47.5\%) were females. As for the remaining 109 uncontrolled DM patients; 63 (57.8\%) of them were males, and $46(42.2 \%)$ were females. The mean age for both groups was $49.2 \pm 12.7$ and $50.1 \pm 12.6$ years, for controlled and uncontrolled patients respectively.

Diabetic patients often suffer from vitamin D deficiency (142 patients), dyslipidemia (104 patients) and hypertension (75 patients). The highest was vitamin D deficiency, 79 (65.8\%) and $63(57.8 \%)$ for controlled and uncontrolled patients, respectively, as seen in table 1.

Hypertension (>140/90 mmhg), Vitamin D Deficiency (< $30 \mathrm{mmol} / \mathrm{L}$ ), Dyslipidemia (Total Cholesterol $>6 \mathrm{mmol} / \mathrm{L}$ ), Hypothyroid (TSH > 10)

As for type 2 DM treatments; different treatments were used oral hypoglycemic, insulin only, insulin \& oral hypoglycemic and diet only, as seen in table 2 .

\section{Results}

The hba1c and FBG were measured at the start and at the end of the study for all patients. Hba1c decreased $15.4 \%$ in controlled DM patients, while it decreased by $6.0 \%$ in uncontrolled DM patients. Showing highly statistical significant results ( $p$-value 0.007) between the two groups. As for FBG, it decreased by $24.9 \%$ and $8.1 \%$ for controlled and uncontrolled respectively, with no significant statistical difference in either groups, as seen in table 3.

For the overall sample, there was a decrease in both hba1c and FBG by $10.7 \%$ and $15.9 \%$ respectively for patients taking oral hypoglycemic, both hba1c and FBG showed a very highly

\begin{tabular}{|c|c|c|c|c|}
\hline \multicolumn{5}{|l|}{ Table 1: Medical History } \\
\hline \multirow{2}{*}{ Medical History* } & \multicolumn{2}{|c|}{ Controlled $(n=120)$} & \multicolumn{2}{|c|}{ Uncontrolled $(n=109)$} \\
\hline & No. & $\%$ of Pts. & No. & $\%$ of Pts. \\
\hline Vitamin D Deficiency & 79 & $65.80 \%$ & 63 & $57.80 \%$ \\
\hline Hypertension & 34 & $28.30 \%$ & 41 & $37.60 \%$ \\
\hline Dyslipidemia & 46 & $38.30 \%$ & 58 & $53.20 \%$ \\
\hline Hypothyroid & 20 & $16.70 \%$ & 8 & $7.30 \%$ \\
\hline Others † & 4 & $3.20 \%$ & 7 & $6.30 \%$ \\
\hline
\end{tabular}

\begin{tabular}{|c|c|c|c|c|c|}
\hline & Total & Controlled & $\%$ & Uncontrolled & $\%$ \\
\hline Oral & 158 & 92 & $76.7 \%$ & 66 & $60.6 \%$ \\
\hline $\begin{array}{l}\text { Insulin and } \\
\text { Oral }\end{array}$ & 56 & 20 & $16.70 \%$ & 36 & $33.0 \%$ \\
\hline Insulin & 11 & 4 & $3.30 \%$ & 7 & $6.4 \%$ \\
\hline Diet only & 4 & 4 & $3.3 \%$ & 0 & $0.0 \%$ \\
\hline Total & 229 & 120 & $100.0 \%$ & 109 & $100.0 \%$ \\
\hline
\end{tabular}

\begin{tabular}{|c|c|c|c|c|c|}
\hline \multicolumn{6}{|c|}{ Table 3: HbA1c \& FBG } \\
\hline & $\begin{array}{l}\text { HbA1c \% } \\
\text { (base line) }\end{array}$ & $\begin{array}{l}\text { HbA1c \% } \\
\text { (end of the } \\
\text { study) }\end{array}$ & $\begin{array}{l}\text { FBG } \\
\text { mmol } \\
\text { (base } \\
\text { line) }\end{array}$ & I/L & $\begin{array}{l}\text { FBG } \\
\text { mmol/L } \\
\text { (end of the } \\
\text { study) }\end{array}$ \\
\hline & \multicolumn{5}{|l|}{ Controlled } \\
\hline $\mathbf{N}$ & 115 & 115 & 77 & \multicolumn{2}{|l|}{77} \\
\hline Mean & 7.7 & 6.5 & 8.4 & \multicolumn{2}{|l|}{6.3} \\
\hline SD & 1.9 & 0.9 & 3 & \multicolumn{2}{|l|}{1.1} \\
\hline Mean Diff. & \multicolumn{2}{|l|}{-1.2} & \multicolumn{3}{|l|}{-2.1} \\
\hline$\%$ change & \multicolumn{2}{|l|}{$-15.4 \%$} & \multicolumn{3}{|c|}{$-24.9 \%$} \\
\hline p-value & \multicolumn{2}{|l|}{0.000} & \multicolumn{3}{|l|}{0.000} \\
\hline \multicolumn{6}{|l|}{ Uncontrolled } \\
\hline $\mathbf{N}$ & 103 & 103 & 55 & 55 & \\
\hline Mean & 9.7 & 9.1 & 11.7 & 10. & \\
\hline SD & 1.7 & 1.5 & 3.7 & 3.3 & \\
\hline Mean Diff. & \multicolumn{2}{|l|}{-0.6} & \multicolumn{3}{|l|}{-0.9} \\
\hline$\%$ change & \multicolumn{2}{|l|}{$-6.0 \%$} & \multicolumn{3}{|l|}{$-8.1 \%$} \\
\hline p-value & \multicolumn{2}{|l|}{0.000} & \multicolumn{3}{|l|}{0.119} \\
\hline $\begin{array}{l}\text { p-value } \\
\text { between } \\
\text { Controlled \& } \\
\text { Uncontrolled }\end{array}$ & \multicolumn{2}{|l|}{0.007} & \multicolumn{3}{|l|}{0.086} \\
\hline
\end{tabular}

statistical significant result regarding diabetes management ( $p$-value 0.000). As for patients taking both insulin \& oral hypoglycemic; there was a decrease in hba1c \& FBG between the start and end of the study, by $-10.7 \%$ and $-20.2 \%$ respectively, hba1c showing a very highly statistical significant results ( $p$-value 0.000) and FBG showing a statistically significant results regarding diabetes control ( $p$-value 0.020). There was also a decrease in hba1c and FBG for patients taking insulin only, by $-7.4 \%$ and $-12.7 \%$ respectively, hba1c showing statistical significance ( $p$-value 0.065) and FBG showing no statistical significance. As for patients who were only regulating diet; there was a decrease in hba1c and an increase in FBG, by $-6.3 \%$ and $3.1 \%$ respectively, with no statistical significant results for both hba1c and FBG. As seen in table 4.

The controlled DM group, total cholesterol, LDL-C, HDL-C, and triglycerides showed percent changes by $-11.2 \%,-11.1 \%$, $19.8 \%,-30.4 \%$, respectively. And for the uncontrolled DM group, showed significant percent changes by $-4.8 \%,-0.8 \%, 3.1 \%$ \& $-3.4 \%$ respectively between first and last visits, as seen in table 5 .

Vitamin D results at base line and at the end of the study for both controlled and uncontrolled was very highly statistically 
significant ( $p$-value $=0.000$ ) when related to diabetes control, as seen in table 6 .

\section{Discussion}

According to the UK Prospective Diabetes Study [UKPDS], controlled DM type 2 patients achieving median of $7.0 \%$ hba1c, have shown a significant reduction in micro-vascular risk of complications and a decrease in myocardial infarction incidence, compared with $7.9 \%$ median of hba1c, over a median of 10 years of follow up. [18] Patients with type 2 diabetes have an increased prevalence of lipid abnormalities, contributing to their high risk of CVD. [22, 23]

In our study; we have measured various parameters to see the contrast between controlled and uncontrolled type 2 diabetic patients. The aim of diabetes control is to maintain normal blood glucose levels and to achieve hba1c of 7.0\%. Hba1c and FBG decreased by the end of the study. Hba1c decreased by $15.4 \%$ in controlled patients, whereas decreased by $6.0 \%$ in uncontrolled DM patients; [ $p=0.007$ ]. FBG also decreased by $24.9 \%$ and $8.1 \%$, for controlled and uncontrolled DM patients.

Previous studies have compared the intensive treatment with conventional treatment. The intensive treatment showed the following results: $12 \%$ reduction $[p=0.029]$ to any diabetes related end point; $10 \%$ reduction $[p=0.34]$ in death related to diabetes; $16 \%$ reduction $[p=0.052]$ in myocardial infarction; $11 \%$ increase $[p=0.52]$ in stroke incidence; and $25 \%$ reduction [ $p=0.0099]$ in microvascular diseases. [24]

Another study performed in Kumamoto, Japan compared 100 randomized type 2 diabetic patients with intensive and conventional insulin therapy, and were followed up for 6 years. The intensively treated group had less retinopathy [13\% vs $38 \%$, $p=0.007]$, nephropathy [ $10 \%$ vs $30 \%, p=0.005]$, and neuropathy $[12.8 \%$ vs $64.6 \%$ increase in lower extremity vibration threshold, $p<0.05]$ than the conventionally treated group. The hba1c levels at the end of the study were $7.1 \%$ vs $9.4 \%$ in the two groups, respectively. [25]

It was also seen that the treatment with metformin showed a significant advantage over the conventional treatment in obese patients [n=1704]: a $32 \%$ reduction of diabetes-related end points [ $p=0.002]$, a $42 \%$ reduction of diabetes-related deaths $[p=0.017]$, and a $36 \%$ reduction of all-cause mortality [ $p=0.011]$. Patients taking metformin also had less weight gain and fewer hypoglycemic attacks than those taking insulin or sulfonylureas. The above results show that the complications in type 2 diabetes are reduced through the reduction of blood glucose. [24] In our study, for patients taking oral hypoglycemic there was a decrease in both hba1c and FBG by $10.7 \%$ and $15.9 \%$ respectively [ $p$-value 0.000]. Also in patients taking both insulin \& oral hypoglycemic; there was a decrease in hba1c \& FBG between the start and end of the study, by $-10.7 \%$ [ $p$ value 0.000$]$ and $-20.2 \%$ [ $p$-value 0.020 ] respectively. As for patients taking insulin only, by $-7.4 \%$ and $-12.7 \%$ for hba1c and FBG respectively, and patients only regulating diet; there was a decrease in hba1c and an increase in FBG, by $-6.3 \%$ and $3.1 \%$ respectively. This conveys how
Table 4: HbA1c \& FBG per Treatment Regimen

\begin{tabular}{|c|c|c|c|c|c|}
\hline & & $\begin{array}{l}\text { HbA1c } \\
\% \\
\text { (base } \\
\text { line) }\end{array}$ & $\begin{array}{l}\text { HbA1c \% } \\
\text { (end of the } \\
\text { study) }\end{array}$ & $\begin{array}{l}\text { FBG } \\
\text { mmol/L }\end{array}$ & $\begin{array}{l}\text { FBG } \\
\text { mmol/L }\end{array}$ \\
\hline \multirow{6}{*}{ Oral } & $\mathrm{N}$ & 149 & 149 & 98 & 98 \\
\hline & Mean & 8.4 & 7.5 & 9.4 & 7.9 \\
\hline & SD & 2.0 & 1.7 & 3.5 & 2.9 \\
\hline & Mean Diff. & \multicolumn{2}{|l|}{-0.9} & \multicolumn{2}{|l|}{-1.5} \\
\hline & $\%$ change & \multicolumn{2}{|l|}{$-10.7 \%$} & \multicolumn{2}{|l|}{$-15.9 \%$} \\
\hline & p-value & \multicolumn{2}{|l|}{0.000} & \multicolumn{2}{|l|}{0.000} \\
\hline \multirow{6}{*}{$\begin{array}{l}\text { Insulin } \\
\text { and Oral }\end{array}$} & $\mathrm{N}$ & 54 & 54 & 27 & 27 \\
\hline & Mean & 9.4 & 8.4 & 11.8 & 9.4 \\
\hline & SD & 2.0 & 1.7 & 4.0 & 4.2 \\
\hline & Mean Diff. & \multicolumn{2}{|l|}{-1.0} & \multicolumn{2}{|l|}{-2.4} \\
\hline & $\%$ change & \multicolumn{2}{|l|}{$-10.7 \%$} & \multicolumn{2}{|l|}{$-20.2 \%$} \\
\hline & p-value & \multicolumn{2}{|l|}{0.000} & \multicolumn{2}{|l|}{0.020} \\
\hline \multirow{6}{*}{ Insulin } & $\mathrm{N}$ & 11 & 11 & 3 & 3 \\
\hline & Mean & 9.2 & 8.5 & 9.1 & 8.0 \\
\hline & SD & 2.2 & 2.1228 & 3.6 & 1.6 \\
\hline & Mean Diff. & \multicolumn{2}{|l|}{-0.7} & \multicolumn{2}{|l|}{-1.2} \\
\hline & $\%$ change & \multicolumn{2}{|l|}{$-7.4 \%$} & \multicolumn{2}{|l|}{$-12.7 \%$} \\
\hline & p-value & \multicolumn{2}{|l|}{0.065} & \multicolumn{2}{|l|}{0.458} \\
\hline \multirow{6}{*}{ Diet only } & $\mathrm{N}$ & 4 & 4 & 4 & 4 \\
\hline & Mean & 6.7 & 6.3 & 7.0 & 7.3 \\
\hline & SD & 0.9 & 0.4 & 1.5 & 1.2 \\
\hline & Mean Diff. & \multicolumn{2}{|l|}{-0.4} & \multicolumn{2}{|l|}{0.2} \\
\hline & $\%$ change & \multicolumn{2}{|l|}{$6.3 \%$} & \multicolumn{2}{|l|}{$3.1 \%$} \\
\hline & p-value & \multicolumn{2}{|l|}{0.383} & \multicolumn{2}{|l|}{0.525} \\
\hline
\end{tabular}

controlling diabetes shows significant difference in regulating both hba1c and FBG.

Another similar trial randomized 153 men with type 2 diabetes to intensive control or standard therapy. At the end of 27 months of follow-up, the mean hba1c values were significantly lower in the intensive group [7.3\% vs 9.4\%; $p<0.001]$. [26] In a previous study, it was illustrated that the median for hba1c was $8.4 \%$ for conventional therapy and 6.9\% for intensive therapy. [27] Also, it was seen that the risk for micro-vascular problems decreases by $37 \%$ and the risk of mortality decreases by $21 \%$ for each $1 \%$ reduction in hba1c. [28-30] The incidence of micro-vascular risk was lower than that of myocardial infarction in patients with the lowest category of mean hba1c.[11] This illustrates how hyperglycemia may be a contributing factor for cardiovascular risk for diabetic patients, rather than only the conventional risks, such as smoking, hypertension and dyslipidemia. [31]

Numerous studies, which were conducted to observe the correlation between Vitamin D insufficiency and type 2 DM, is recently being investigated to see the links and correlation between them. ${ }^{[32-33]}$ Vitamin D insufficiency is common in type 2 DM patients, resulting in lowering insulin secretion from the pancreas, however with no alterations in glucagon secretion. [34] Evidence show that supplementation of vitamin D in type 2 DM patients improves impaired glucose tolerance and insulin resistance through increasing the release of pancreatic insulin by 


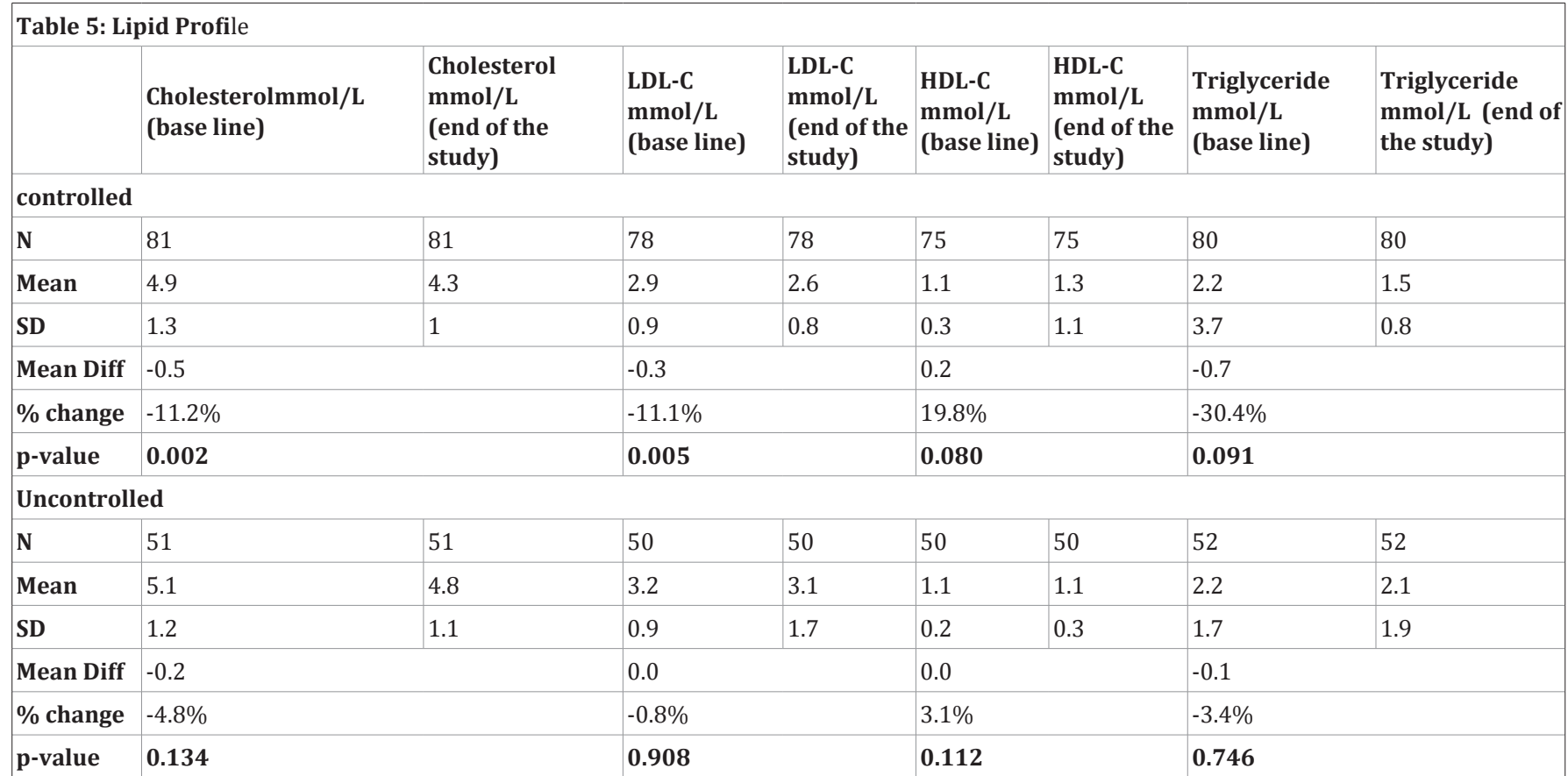

Table 6: Vitamin D \& S. Calcium

\begin{tabular}{|l|l|l|l|l|}
\hline & $\begin{array}{l}\text { Vitamin D } \\
\text { ng/ml } \\
\text { (base line) }\end{array}$ & $\begin{array}{l}\text { Vitamin D ng/ } \\
\text { ml } \\
\text { (end of the } \\
\text { study) }\end{array}$ & $\begin{array}{l}\text { Serum } \\
\text { Calcium } \\
\text { mmol/L } \\
\text { (base line) }\end{array}$ & $\begin{array}{l}\text { Serum } \\
\text { Calcium } \\
\text { mmol/L } \\
\text { (end of the } \\
\text { study) }\end{array}$ \\
\hline Controlled & \multicolumn{2}{|l|}{} \\
\hline N & 62 & 62 & 71 & 71 \\
\hline Mean & 31.3 & 70.3 & 2.2 & 2.2 \\
\hline SD & 13.6 & 27.5 & 0.1 & 0.3 \\
\hline $\begin{array}{l}\text { Mean } \\
\text { Diff }\end{array}$ & 39.0 & & 0.0 & \\
\hline $\begin{array}{l}\text { \% } \\
\text { change }\end{array}$ & $124.3 \%$ & & $-0.3 \%$ & \\
\hline p-value & $\mathbf{0 . 0 0 0}$ & & $\mathbf{0 . 8 3 2}$ & \\
\hline Uncontrolled & & & \\
\hline N & 39 & 39 & 50 & 50 \\
\hline Mean & 31.4 & 69.6 & 2.3 & 2.3 \\
\hline SD & 9.5 & 32.5 & 0.1 & 0.1 \\
\hline $\begin{array}{l}\text { Mean } \\
\text { Diff }\end{array}$ & 38.2 & & 0.0 & \\
\hline$\%$ & $121.4 \%$ & & $0.9 \%$ & \\
\hline change & p-value & $\mathbf{0 . 0 0 0}$ & & $\mathbf{0 . 1 0 9}$ \\
\hline
\end{tabular}

stimulating its synthesis in pancreatic islets. [34-35] There are data that also link and suggest that low vitamin D level might be causally linked to impaired insulin sensitivity.[36-38] It was also found that endothelial function, which is a powerful marker for cardiovascular risk is improved with vitamin D supplementation. [34] In our study vitamin D was investigated in both uncontrolled and controlled groups, it was shown to increase Vitamin D level by; $121.4 \%$ and $124.3 \%$ respectively, both showing very highly significant results in our study [ $p$-value 0.000$]$, that vitamin D status has an effect on diabetes mellitus type 2 control. Vitamin D enhances calcium reabsorption by the kidney and increases the ingested calcium uptake by the gut, leading to the increase of both minerals in the plasma. [39] So, previous studies were made to see the effect of Vitamin D on insulin and its resistance, however in our study we investigate the effect of diabetes control on vitamin D levels and by subsequence the effect on Calcium levels.

Numerous studies have also been made on the correlation between calcium status and diabetes. It has been found that calcium levels are lower in diabetic patients compared to control non-diabetic patients. [40] It was also seen in some prospective studies that low calcium intake is inversely correlated with type 2 DM incidence. [41-44] However, in our study serum calcium showed non-significant results when related to diabetes in either groups $p=0.109$ and $p=0.832$ for the uncontrolled group and controlled group, respectively.

Dyslipidemia is one of the main diseases that accompany Diabetes Mellitus, so lipid concentration is a marker of the condition. A prior study illustrated that improved glycemic control has been shown to lower LDL_C levels, [45-48] which theoretically should lower the risk of developing CHD for patients with diabetes. [49-52] In this study, it was seen that controlled patients showed a better lipid profile than uncontrolled patients, since total cholesterol, LDL-C and Triglyceride [TG] levels declined more in controlled patients and HDL-C increased more in controlled patients. The cholesterol level decreased from base line to the end of the study by $4.8 \%$ and $11.2 \%$, for uncontrolled [ $p$-value 0.134] and controlled [ $p$-value 0.002] patients 
respectively. LDL-C decreased markedly in controlled patients than in uncontrolled patients, by $11.1 \%$ and $0.8 \%$, respectively. Also, TG decreased by $3.4 \%$ on uncontrolled patients, while was decreased by $30.4 \%$ in controlled patients. As for HDL-C, it increased by $19.8 \%$ in controlled patients but only by $3.1 \%$ in uncontrolled patients.

\section{Conclusion}

Controlled diabetic patients showed better clinical outcomes than uncontrolled patients regarding lipid profile, hba1c, FBG and Vitamin D deficiency. Strict diabetes control regulates TG, LDL-C and HDL-C, which in turn decreases CV risk.

\section{References}

1. Neel JV. Diabetes mellitus: a "thrifty" genotype rendered detrimental by "progress"? Am J Hum Genet. 1962;14(4):353-362.

2. HuFB, Manson JE, Stampfer MJ, Colditz G, Liu S, Solomon CG, et al,. Diet, lifestyle, and the risk of type 2 diabetes mellitus in women. $\mathrm{N}$ Engl J Med. 2001;345(11):790-797.

3. Hamman RF. Genetic and environmental determinants of noninsulin dependent diabetes mellitus (NIDDM). Diabetes Metab Rev. 1992;8(4):287-338.

4. Stern MP. Kelly West Lecture: primary prevention of type II diabetes mellitus. Diabetes Care 1991;14(5):399-410.

5. Benjamin SM, Valdez R, Geiss LS, Rolka DB, Narayan KM. Estimated number of adults with prediabetes in the US in 2000: opportunities for prevention. Diabetes Care. 2013;26(3):645-649.

6. Klein R. Hyperglycemia and microvascular and macrovascular disease in diabetes. Diabetes Care. 1995; 18(2):258-268.

7. Pirart J. Diabetes mellitus and its degenerative complications: a prospective study of 4,400 patients observed between 1947 and 1973(part 1). DiabetesCare. 1977;3(4):245256.

8. Standl E, Balletshofer B, Dahl B, Weichenhain B, Stiegler H, Hormann A, et al. Predictors of 10year macrovascular and overall mortality in patients with NIDDM: the Munich general practitioner project. Diabetologia. 1996;39(12):1540-1505.

9. Groeneveld Y, Petri H, Hermans J, Springer MP. Relationship between blood glucose level and mortality in type 2 diabetes mellitus: a systematic review. Diabet Med 1999;16(1): 2-13.

10. Lehto S, Ronnemaa T, Pyörälä K, Laakso M. Predictors of stroke in middleaged patients with noninsulindependent diabetes. Stroke 1996;27(1):63-68.

11.UKPDS Group. Risk factors for coronary artery disease in noninsulin dependent diabetes (UKPDS 23). BMJ. 1998; 316(7134):823-828.

12. Wei M, Gaskill SP, Haffner SM, Stern MP. Effects of diabetes and level of glycaemia on allcause and cardiovascular mortality. Diabetes Care. 1998;21(7):11671172.

13. Balkau B, Shipley M, Jarrett RJ, Pyorala K, Pyorala M, Forhan A, et al. High blood glucose concentration is a risk factor for mortality in middle aged nondiabetic men. Diabetes Care. 1998;21(3):360-367.

14. Krolewski AS, Laffel LM, Krolewski M, Quinn M, Warram JH. Glycosylated hemoglobin and the risk of microalbuminuria in patients with insulindependent diabetes mellitus. N Engl J Med. 1995;332(19):1251-1255.

15. Fox CS, Coady S, Sorlie PD, D’Agostino Sr RB, Pencina MJ, Vasan RS, et al. Increasing cardiovascular disease burden due to diabetes mellitus: the Framingham Heart Study. Circulation. 2007;115(12): 1544- 1550.

16. Selvin E, Marinopoulos S, Berkenblit G, Rami T, Brancati FL, Powe NR, et al. Meta-analysis: glycosylated hemoglobin and cardiovascular disease in diabetes mellitus. Ann Intern Med. 2004;141(6): 421-431.

17. American Diabetes Association. Standards of medical care in diabetes - 2007. Diabetes Care 2007;30(Suppl):S4-S41.DOI: dx.doi. org/10.2337/dc07-S004.

18. International Diabetes Federation. Saudi Arabia [Internet]. Available from: Cited 2015 Jan 13.

19. Alzaid A. Time to declare war on diabetes. Annals of Saudi Medicine 1997; 17: 154-155.

20. Diabetes Health Center. "The Hemoglobin A1c (HbA1c) Test for Diabetes" Last updated 2012 May. Cited: 2015 Jan 13.

21.UKPDS Group. Intensive blood glucose control with sulphonylureas or insulin compared with conventional treatment and risk of complications in patients with type 2 diabetes (UKPDS 33). Lancet. 1998;352(9178):837853.

22. Baigent, Keech A, Kearney PM, Blackwell L, Buck G, Pollicino C, et al. Efficacy and safety of cholesterol-lowering treatment: prospective meta-analysis of data from 90,056 participants in 14 randomised trials of statins. Lancet. 2005;366(9493):1267-1278.

23. Mihaylova B, Emberson J, Blackwell L, Keech A, Simes J, Barnes EH, et al. The effects of lowering LDL cholesterol with statin therapy in people at low risk of vascular disease: meta-analysis of individual data from 27 randomised trials. Lancet. 2012;380(9841):581-590. DOI: 10.1016/S0140-6736(12)60367-5.

24. Markku Laakso. Benefits of Strict Glucose and Blood Pressure Control in Type 2 Diabetes Lessons From the UK Prospective Diabetes Study. Circulation. 1999;99:461-462.

25. Ohkubo Y, Kishikawa H, Araki E, Miyata T, Isami S, Motoyoshi S, et al. Intensive insulin therapy prevents the progression of diabetic microvascular complications in Japanese patients with non-insulin dependent and insulin-dependent diabetes mellitus. Ann Intern Med. 1996; 124:104-109.

26. Abraira C, Colwell JA, Nuttall FQ, Sawin CT, Nagel NJ, Comstock JP, et al. Veterans Affairs Cooperative Study on glycemic control and complications in type II diabetes (VA CSDM); results of the feasibility trial. Diabetes Care. 1995;18(8): 1113-1123.

27. William Duckworth, Carlos Abraira, Thomas Moritz, Domenic Reda, Nicholas Emanuele, Peter D. Reaven, et.al. Glucose Control and Vascular Complications in Veterans with Type 2 Diabetes. N Engl J Med. 2009;360(2):129-139.DOI: doi: 10.1056/NEJMoa0808431.

28. UKPDS Group. Tight blood pressure control and risk of macrovascular and microvascular complications in type 2 diabetes (UKPDS 38). BMJ. 1998;317(7160):703713.

29. MacMahon S, Peto R, Cutler J, Collins R, Sorlie P, Neaton J, et al. Blood pressure, stroke, and coronary heart disease. Part 1: prolonged differences in blood pressure: prospective observational studies corrected for the regression dilution bias. Lancet. 1990;335(8692):765-774.

30. Adler AI, Stratton IM, Neil HAW, Yudkin JS, Matthews DR, Cull CA, et al. Association of systolic blood pressure with macrovascular and micro vascular complications of type 2 diabetes (UKPDS 36): prospective observational study. BMJ. 2000; 321(7258):412-419. 
31.Stamler J. Epidemiology, established major risk factors and the primary prevention of coronary heart disease. In: Parmley WW, Chatterjee K, eds. Cardiology. Philadelphia: JB Lippincott. 1987:141.

32. Scragg R, Sowers M, Bell C. Serum 25-hydroxyvitamin D, diabetes, and ethnicity in the third national health and nutrition examination survey. Diabetes Care. 2004; 27(12): 2813-2818.

33. Di Cesar DJ, Ploutz-Snyder R, Weinstock RS, Moses AM. Vitamin D deficiency is more common in Type 2 than in Type 1 diabetes. Diabetes Care. 2006; 29(1): 174.

34. Borissova AM, Tankova T, Kirilov G, Dakovska L, Kovacheva R. The effect of vitamin D3 on insulin secretion and peripheral insulin sensitivity in Type 2 diabetic patients. Int J Clin Pract. 2003; 57(4) 258-261.

35. Boucher BJ. Inadequate vitamin D status: does it contribute to the disorders comprising syndrome 'X'? Br J Nutr. 1998; 79(4):315-327.

36. Cigolini M, Iagulli MP, Miconi V, Galiotto M, Lombardi S, Targher G. Serum 25-hydroxyvitamin D3 concentrations and prevalence of cardiovascular disease among Type 2 diabetic patients. Diabetes Care. 2006; 29(3): 722-724.

37. Baynes KC, Boucher BJ, Feskens EJ, Kromhout D. Vitamin D, glucose tolerance and insulinaemia in elderly men. Diabetologia. 1997;40(3):344-347.

38. Mathieu C, Gysemans C, Giulietti A, Bouillon R. Vitamin D and diabetes. Diabetologia. 2005;48(7):1247-1257.

39. Deluca HF, Cantorna MT. Vitamin D: its role and uses in immunology. FASEB J. 2001; 15(14): 2579-2585.

40. Widlansky ME, Gokce N, Keaney JF Jr, Vita J. The clinical implications of endothelial dysfunction. J Am Coll Cardiol. 2003; 42(7): 1149-1160.

41. Isaia G, Giorgino R, Adami S. High prevalence of hypovitaminosis D in female type 2 diabetic population. Diabetes Care. 2001; 24(8):1496.

42. Pittas AG, Dawson-Hughes B, Li T, Van Dam RM, Willett WC, Manson JE, Hu FB. Vitamin D and calcium intake in relation to type 2 diabetes in women. Diabetes Care. 2006; 29(3):650-656.
43. Liu S, Song Y, Ford ES, Manson JE, Buring JE, Ridker PM. Dietary calcium, vitamin $\mathrm{D}$, and the prevalence of metabolic syndrome in middleaged and older U.S. women. Diabetes Care. 2005; 28(12):29262932.

44. Colditz GA, Manson JE, Stampfer MJ, Rosner B, Willett WC, Speizer FE. Diet and risk of clinical diabetes in women.AmJ Clin Nutr. 1992;55(5):1018-1023.

45. van Dam RM, Hu FB, Rosenberg L, Krishnan S, Palmer JR. Dietary calcium and magnesium, major food sources, and risk of type 2 diabetes in U.S. black women. Diabetes Care. 2006;29(10):22382243.

46. University Group Diabetes Program. Effects of hypoglycemic agents on vascular complications in patients with adult-onset diabetes. Diabetes. 1982;31(Suppl 5):1-81.

47. DeFrozo RA, Goodman AM. Efficacy of metformin in patients with noninsulin dependent diabetes mellitus: the Multicenter Metformin Study Group. N Engl J Med. 1995;333(9):541-549.

48. Taskinen MR, Kuusi T, Helve E, Nikkila EA, Yki JH. Insulin therapy induces antiatherogenic changes of serum lipoproteins in noninsulindependent diabetes. Arteriosclerosis. 1988;8(2):168-177.

49. Agardh CD, Nilsson EP, Schersten B. Improvement of the plasma lipoprotein pattern after institution of insulin treatment in diabetes mellitus. Diabetes Care. 1982;5(3): 322-325. DOI:dx.doi. org/10.2337/diacare.5.3.322.

50. Uusitupa MI, Niskanen LK, Siitonon O, Voutilainen E, Pyorala K Ten-year cardiovascular mortality in relation to risk factors and abnormalities in lipoprotein composition in type 2 (non-insulindependent) diabetic and non-diabetic subjects. Diabetologia. 1993;36(11):1175-1184.

51. Stern MP, Haffner SM. Dyslipidemia in type II diabetes: implications for therapeutic intervention. Diabetes Care. 1991;14(12):1144-1159.

52. Barak Gaster, Irl B. Hirsch. The Effects of improved glycemic control on complications in type 2 diabetes. The Journal of Clinical Endocrinology \& Metabolism. 92(6):2017-2029. 